\title{
Experimental Study of Actual Delivered Density for Rack-Storage Fires
}

\author{
TAK-SANG CHAN, HSIANG-CHENG KUNG, HONG-ZENG YU and WILLIAM R. BROWN \\ Factory Mutual Research Corporation \\ 1151 Boston-Providence Turnpike \\ Norwood, Massachusetts 02062, USA
}

\begin{abstract}
The Actual Delivered Density (ADD) for rack-storage fires has been investigated experimentally, using an ADD apparatus equipped with a fire plume simulator. The fire plume simulator was calibrated to simulate the plumes of a $6.1-\mathrm{m}(20-\mathrm{ft})$ high rack-storage fire of the FMRC Class II Commodity. Three standard upright sprinklers (17/32-in. C, 1/2-in F \& 1/2-in. G) were employed for the investigation. Empirical correlations in the form of power law for the water penetration ratio, which is the ratio of the ADD to the water density measured without fire, have been established for sprinkler-fire arrangements in which the fire was centered under one sprinkler, centered below two sprinklers on the same pipe and centered below four sprinklers. In the case of a single sprinkler operation, the water penetration ratios for a given sprinkler and fire size were found independent of the water discharge rate under the present measurement range, varying from $95 \mathrm{l} / \mathrm{min}$ to $212 \mathrm{l} / \mathrm{min}$ (25 gpm to $56 \mathrm{gpm})$.
\end{abstract}

KEYWORDS: Actual Delivered Density, Rack Storage Fire, Fire Plume Simulation, Sprinklered Fire, Heptane-Spray Fire.

\section{INTRODUCTION}

Over the last two decades, warehousing of industrial products has undergone dramatic changes such as the introduction of a new generation of storage products consisting of flammable synthetic materials, and the increasing heights of rack storage arrangements. Fires in this "new environment" are characterized by extremely high heat release rates and fire plumes with velocities over $10 \mathrm{~m} / \mathrm{s}$. Due to the increasing challenge by these fires, sprinkler systems which used to be able to suppress fires of light and ordinary hazard occupancies are no longer capable of suppressing these high-challenge rack storage fires. To advance the design of sprinkler systems under this new environment, a quantitative evaluation of sprinkler performance is needed. 
The Actual Delivered Density (ADD) concept was first introduced by FMRC in its Early Suppression Fast Response (ESFR) research program [1] as a means of predicting sprinkler performance. The ADD of a sprinkler is the water density actually penetrating the fire plume and delivered to the top surface of a buming rack-storage commodity. The ADD depends on the plume characteristics, heat release rate, ignition location, ceiling clearance, water discharge rate, spray pattern and drop size distribution. Fire suppression is expected if the $\mathrm{ADD}$ is greater than the Required Delivered Density (RDD), which is the density required to be delivered to the top surface of the burning rack-storage fire to achieve fire suppression.

Therefore, knowledge of the ADD variation under various fire situations is essential in order to predict sprinkler performance. To date, correlations for the ADD variation have rarely been established. The only related work was carried out by Heskestad [2] in his laboratory study on the sprinkler spray/plume interaction. In his experiments, a simulated buoyant plume was generated by a non-reacting fire plume simulator. Only one sprinkler-fire arrangement in which the simulated plume was centered among four discharging sprinklers was investigated.

Heskestad identified a parameter which separated the operation of the sprinklers into two regimes: a gravitational regime and a momentum regime. In the gravitational regime, water drops from the sprinkler entered the fire plume with their terminal velocity and had no other effects on the plume than moderate cooling of the plume gas. If the plume gas flow created a drag force on the drops greater than the force of gravity, the motion of the water drops would be reversed and swept away outside of the plume. A correlation for the water penetration ratio, which is the ratio of the water density with fire to that without fire, was established in this regime based on a dimensional analysis of pertinent variables. In the momentum regime, the plume gas flow was affected by the downward thrust force of the sprinkler spray as a result of high water density and discharge pressure.

Since correlations of the ADD for rack-storage fires were not available, the objective of this study is to establish such correlations. In this paper, the correlations are presented for three sprinkler-fire arrangements in which the fire was centered under a single sprinkler, centered below two sprinklers on the same pipe and centered below four sprinklers.

\section{MEASUREMENTS}

In this study, a total of 380 experiments were performed to investigate the Actual Delivered Density through simulated rack-storage fires as affected by the fire heat release rate, water discharge rate and configuration of the sprinkler-fire location. Three standard upright sprinkler models, designated as models 17/32-in. C, 1/2-in. F and 1/2-in. G, were employed in the measurements. Model $\mathrm{C}$ has an orifice diameter of $20 \mathrm{~mm}$ nominal, whereas models $F$ and $G$ have nominal orifice diameters of $15 \mathrm{~mm}$. Model $F$ has the same deflector as that of Model C, but with smaller supporting arms. The measurements were performed for three configurations in which a simulated rack-storage fire was centered below one sprinkler, centered below two sprinklers on the same pipe and centered below four sprinklers. For each configuration, measurements were performed for five convective heat release rates $(0,500$, $1000,1500$ and $2000 \mathrm{~kW})$ and four water discharge rates per sprinkler $(95,140,170$ and 212 $l / \mathrm{min})$. 
Figure 1 shows a top view of the experimental apparatus, which will be referred to as the ADD apparatus hereafter, used in the present investigation. The ADD apparatus consists of two parts: 1) a fire plume simulator and 2) a water collection assembly. The fire plume simulator is an assembly of nine nozzles using heptane as fuel. Eight nozzles are equally spaced on a $1.22-\mathrm{m}$ diameter circle and one nozzle is located above a $10.2-\mathrm{cm}$ air deflecting plate at the center of the circle. Under the $10.2-\mathrm{cm}$ plate is an 20.3-cm opening for air supply. Nozzles of various capacities are used to provide the selected convective heat release rates. Heptane is supplied from a fuel tank, which is pressurized by a nitrogen cylinder, to the nozzles in $6.4 \mathrm{~mm}$ copper tubes of equal length, so that each nozzle discharges heptane at the same flow rate. A $12.7-\mathrm{mm}$ water jacket is used to cool the portion of the copper tubing that is above the pan assembly. The water collection assembly consists of twenty pans which are assembled to simulate the top surface of a two-pallet loads wide and two-pallet loads deep rack-storage fuel array, including the flue space between the pallets. Water collected in each pan was channeled to a graduated container via a 19-mm PVC hose.

The heptane spray nozzles are positioned $15.2 \mathrm{~cm}$ above the water collection pans. The outside eight nozzles are directed radially toward the center line of the apparatus. The nozzle angles to the horizontal plane are varied depending on the heat release rates of the simulated plumes. Air is supplied to the center of the nozzle assembly through an air supply duct connected to a blower situated near the south wall of the building. The volumetric flowrate of the air in the duct was measured to be $307 \mathrm{l} / \mathrm{s}$. The undersides of the water collection pans are cooled by water spray nozzles.

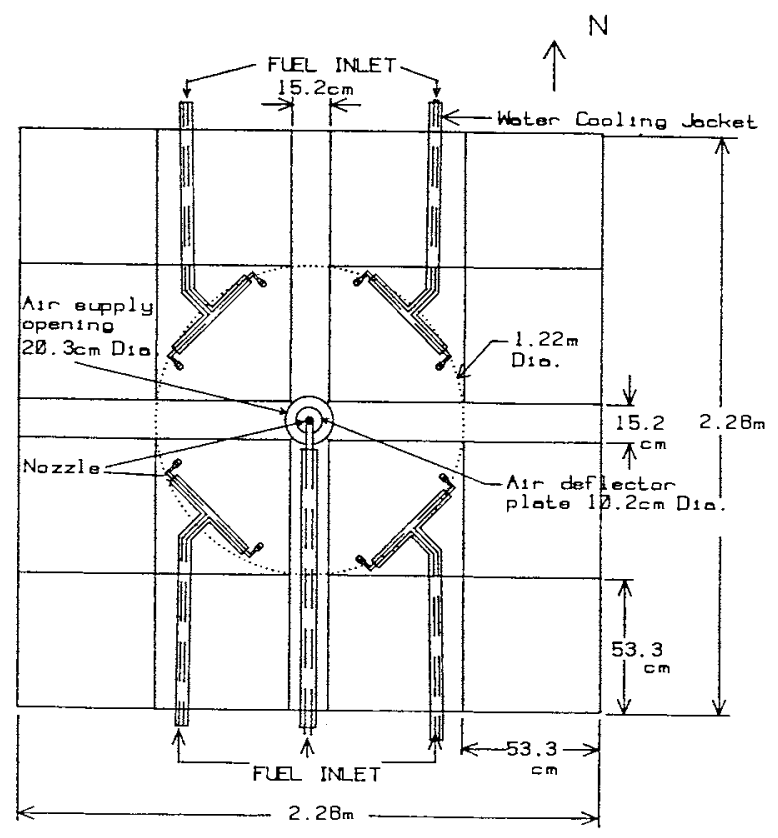

Figure 1. Plan view of the ADD apparatus. 
The measurements were conducted at a FMRC Norwood test building under a $9.93 \mathrm{~m} \times 11.23$ $\mathrm{m}$ suspended ceiling. The ceiling can be raised or lowered to provide floor-to-ceiling clearances of $3.05 \mathrm{~m}, 4.57 \mathrm{~m}, 6.10 \mathrm{~m}, 7.62 \mathrm{~m}$ and $8.53 \mathrm{~m}$. The sprinklers were installed on sprinkler pipes of nominal $5.08-\mathrm{cm}$ diameter under the suspended ceiling via threaded bushings. The centerline of the sprinkler pipes were $31.8 \mathrm{~cm}$ below the ceiling. The two deflector-supporting arms of each sprinkler were aligned with the sprinkler pipe. For all the measurements, the suspended ceiling was maintained at $4.57 \mathrm{~m}$ above the floor, $3.05 \mathrm{~m}$ above the water collection pans.

Before each measurement, water was discharged through the open sprinkler and the pressure was adjusted to the designated value. After the sprinkler stopped dripping, all the graduated containers receiving water from the collection pans were emptied. The heptane spray was then ignited and allowed to burn for forty seconds before discharging water through the sprinkler. After water started to discharge from the sprinkler, the test continued for five additional minutes. Then the water flow to the sprinkler and the fuel to the simulator were shut off. Smoke inside the building was cleared before the next measurement.

\section{CALIBRATION OF THE FIRE PLUME SIMULATOR}

The fire plumes generated by the fire plume simulator were calibrated to simulate various plume stages of a 6.1-m high rack-storage fire of the FMRC Class II Commodity (metal-lined double triwall cartons on pallets). This is accomplished by matching the temperature and velocity measurements of the heptane-spray fire plumes at three elevations with those of the large-scale fire tests. The plume characteristics of the large-scale fire were measured in detail and reported in [3]. These data are used as a benchmark for the calibration of the present fire plume simulator.

\subsection{Calibration Setups}

The calibration was performed at the same test building as described in section 2 prior to the measurements of the actual delivered density. During the calibration, the suspended ceiling was raised to $7.62 \mathrm{~m}$ above the floor. Figure $2 \mathrm{a}$ shows the elevations for the temperature and velocity measurements. The calibrations were performed for five selected "freeburn" convective heat release rates of $500,1000,1500,2000$ and $2500 \mathrm{~kW}$. The convective heat release rate of the heptane-spray fire without sprinkler spray is called the "freeburn" convective heat release rate, which is determined by the calibrated heptane supply flowrate as detailed in [4]. The positions of the thermocouples with respect to the vertical centerline of the ADD apparatus are shown in Figure $2 \mathrm{~b}$. All thermocouples were fabricated from 28gage, inconel-sheathed chromel-alumel thermocouple wires. Centerline plume velocities were measured at the same three elevations using bi-directional probes connected to individual pressure transducers (Setra, model 164). The probe positions are also shown in Figure $2 \mathrm{~b}$.

\subsection{Calibration Results}

Various nozzle configurations were attempted in order to match both the temperature and 
(a)
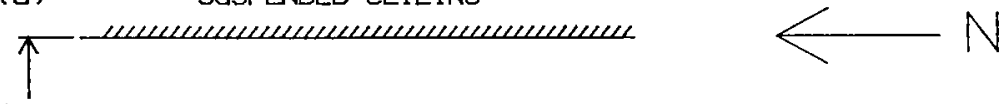

$1.4 \mathrm{~m}$
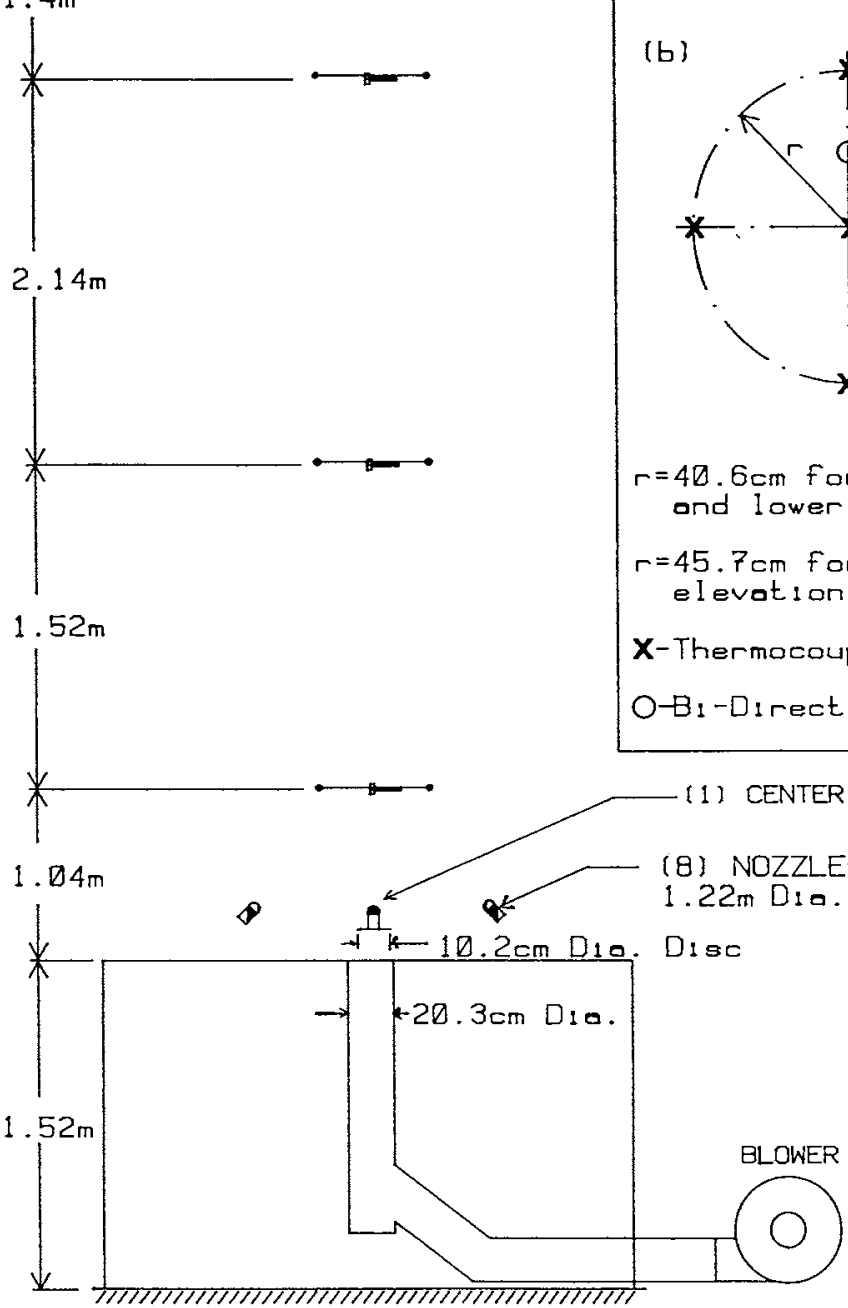

FLOOR

Figure 2. a) Calibration of the simulated plumes, b) Locations of thermocouple and bi-direction probe relative to the water collection apparatus centerline. 
velocity of the heptane-spray fire plume with those of the rack-storage fire plume for all the measurement elevations. The configurations included variations in the number of nozzles, the angle of the nozzles with respect to the horizontal plane, the height of the nozzles above the water collection pans, and the spacing of the nozzles. With the operating conditions listed in Table 1, the excess gas temperature above ambient and velocity of heptane-spray fire plume are shown in Table 2. The off-center temperature is the average of the four locations shown in Figure 2b. For comparison, the data of the rack storage fire plume [3] are also presented in the tables, enclosed with parenthesis.

TABLE 1. Operating Conditions for The Heptane-Spray Nozzles.

\begin{tabular}{||c|c|c|c|c|}
\hline $\begin{array}{c}\text { Convective } \\
\text { Heat Release } \\
\text { Rate (kW) }\end{array}$ & $\begin{array}{c}\text { Center Nozzle } \\
\text { Model Series - } \\
\text { Rated } l / \mathrm{hr} \\
\text { @ 690 kPa }\end{array}$ & $\begin{array}{c}\text { Outside Nozzle } \\
\text { Model Series - } \\
\text { Rated } / \mathrm{hr} \\
\text { @ 690 kPa }\end{array}$ & $\begin{array}{c}\text { Outside Nozzle } \\
\text { Angles to } \\
\text { Horizontal } \\
\text { Plane (deg.) }\end{array}$ & $\begin{array}{c}\text { Heptane } \\
\text { Supply } \\
\text { Pressure } \\
\text { (kPa) }\end{array}$ \\
\hline \hline 500 & PL - 15.1 & PL - 15.1 & 60 & 303 \\
\hline 1000 & PL - 28.4 & PL - 28.4 & 60 & 379 \\
\hline 1500 & PLP - 73.8 & PL - 28.4 & 70 & 586 \\
\hline 2000 & PLP - 73.8 & PL - 58.7 & 55 & 358 \\
\hline 2500 & PLP - 73.8 & PL - 58.7 & 65 & 544 \\
\hline
\end{tabular}

`Monarch Mfg Works, Inc., Philadelphia, PA 19134.

As seen in Table 2, the centerline velocities of the simulated plumes were reasonably matched with those of the rack-storage fire plumes for all the elevations. The centerline excess gas temperature and the off-center excess temperature measurements of the heptane-spray fire plume also agree satisfactorily with those of the rack-storage fire plume for the upper two elevations. At the elevation of $1.04 \mathrm{~m}$ above the top surface of the fuel array, the excess temperature measurements of the heptane-spray fire plume appear to be quite high as compared to those of the rack-storage fire plume. However, the temperature effect on the ADD due to this discrepancy can be considered insignificant as it was estimated [4] that for a temperature increase as high as $600{ }^{\circ} \mathrm{C}$, the reduction in drop size was about $10 \%$ for a 0.5 $\mathrm{mm}$ droplet and diminished rapidly to about $1 \%$ as the drop size was increased to $1.5 \mathrm{~mm}$. Additional information on the fire plume simulator can be found in [4].

\section{EXPERIMENTAL RESULTS AND DATA CORRELATIONS}

In this paper, we present the Actual Delivered Density (ADD) over the central portion of the water collection area (plume area) under the heptane-spray nozzle arrangement. The water flux distribution over the entire water collection area was detailed in [4]. Typical ADD variations with the freeburn convective heat release rate of the simulated plume are presented in Figure 3. The ADDs under no-fire condition shown in the figure will be referred to as the Local Applied Density (LAD) in the following discussion. 

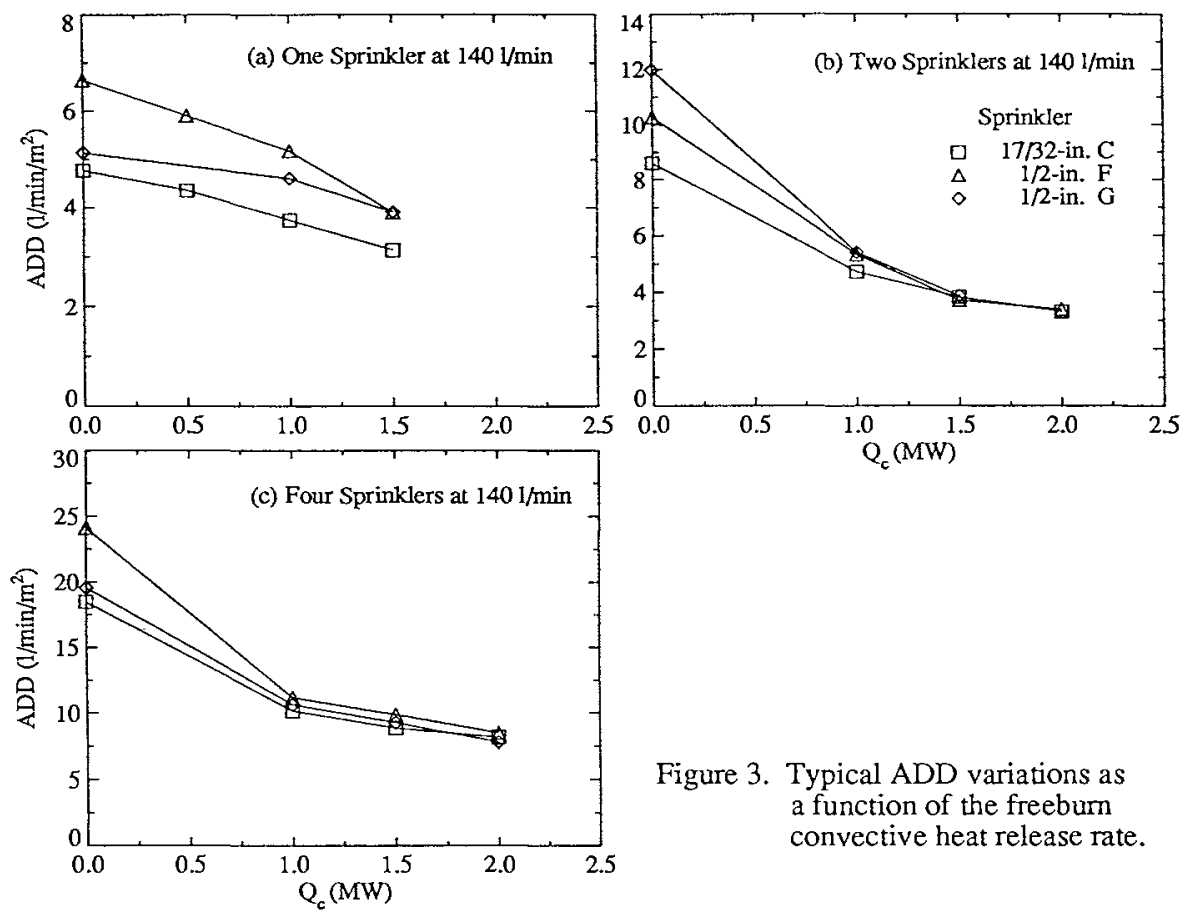

Figure 3. Typical $\mathrm{ADD}$ variations as a function of the freebum convective heat release rate.

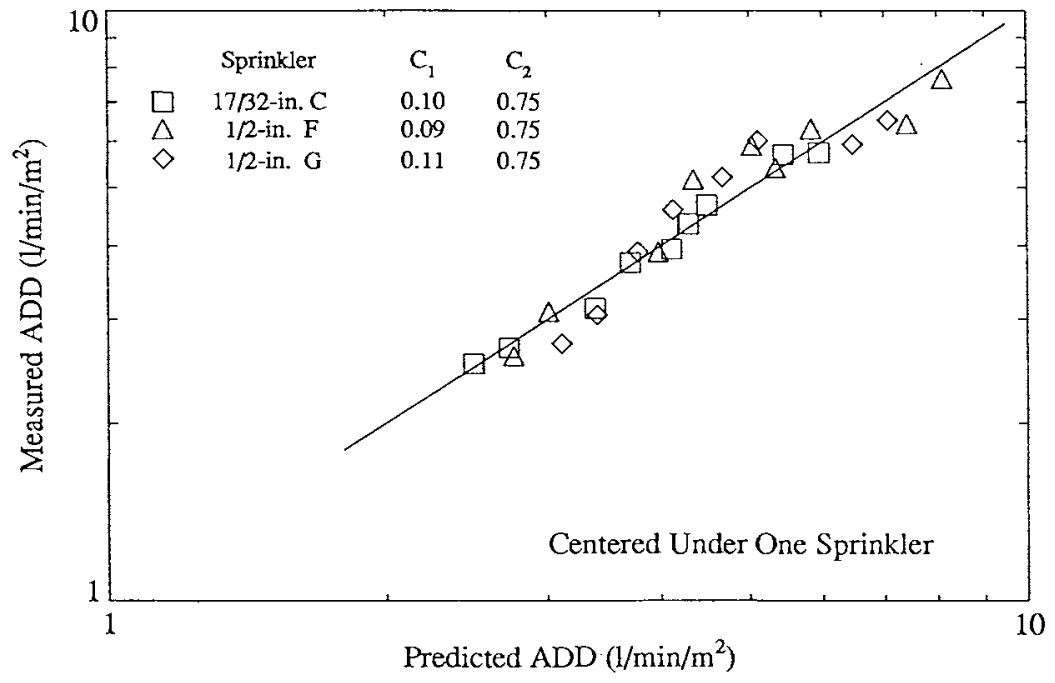

Figure 4. Prediction of ADD according to equation (2) for the case when the fire was directly under a single sprinkler. 
TABLE 2. Excess Gas Temperatures $\left({ }^{\circ} \mathrm{C}\right)$ and Velocities $(\mathrm{m} / \mathrm{s})$ for The Simulated Plumes.

\begin{tabular}{||c|c|c|c|c|c|c|c|c|c||}
\hline \multirow{3}{*}{$\mathrm{Q}_{\mathrm{c}}$} & \multicolumn{6}{|c|}{ Measurement Elevations Above Water Collecting Pans } \\
\cline { 2 - 11 }$(\mathrm{kW})$ & \multicolumn{3}{|c|}{$1.04 \mathrm{~m}$} & \multicolumn{3}{c|}{$2.56 \mathrm{~m}$} & \multicolumn{3}{c|}{$4.70 \mathrm{~m}$} \\
\cline { 2 - 11 } & $\Delta \mathrm{T}_{\mathrm{c}}$ & $\Delta \mathrm{T}_{\mathrm{o}}$ & $\mathrm{u}_{\mathrm{p}}$ & $\Delta \mathrm{T}_{\mathrm{c}}$ & $\Delta \mathrm{T}_{\mathrm{o}}$ & $\mathrm{u}_{\mathrm{p}}$ & $\Delta \mathrm{T}_{\mathrm{c}}$ & $\Delta \mathrm{T}_{\mathrm{o}}$ & $\mathrm{u}_{\mathrm{p}}$ \\
\hline \hline 500 & 182 & 466 & 7.6 & 181 & 145 & 6.7 & 112 & 82 & 5.9 \\
& $(330)$ & $(207)$ & $(7.3)$ & $(162)$ & $(104)$ & $(6.5)$ & $(94)$ & $(54)$ & $(6.2)$ \\
\hline 1000 & 421 & 875 & 9.1 & 376 & 284 & 8.9 & 203 & 152 & 7.5 \\
& $(675)$ & $(415)$ & $(9.6)$ & $(331)$ & $(198)$ & & $(162)$ & $(103)$ & $(7.6)$ \\
\hline 1500 & 792 & 1012 & 10.4 & 556 & 380 & 10.1 & 274 & 208 & 8.7 \\
& $(846)$ & $(524)$ & $(10.5)$ & $(524)$ & $(300)$ & $(9.5)$ & $(253)$ & $(156)$ & $(9.1)$ \\
\hline 2000 & 896 & 1048 & 10.5 & 760 & 533 & 11.8 & 373 & 275 & 9.9 \\
& $(891)$ & $(656)$ & $(10.7)$ & $(723)$ & $(333)$ & $(11)$. & $(355)$ & $(207)$ & $(10.7)$ \\
\hline 2500 & 889 & 1121 & 10.8 & 846 & 671 & 12.5 & 427 & 318 & 10.5 \\
& $(915)$ & $(692)$ & $(10.8)$ & $(810)$ & $(468)$ & $(9.1)$ & $(408)$ & $(245)$ & $(11)$ \\
\hline
\end{tabular}

As expected, the ADDs decrease as the freeburn fire heat release rate is increased. For the case where the fire was centered under a single sprinkler, the ADDs provided by the two 1/2in. sprinklers are comparable, even though the LADs of the two sprinklers differ considerably. The ADDs provided by the large-orifice $C$ sprinkler are consistently lower than those provided by the $1 / 2$-in. sprinklers in this case. For the two-and four- sprinkler arrangements, the ADDs provided by the three sprinklers are in general comparable with one another, also with the C model ADDs being somewhat less than the others'.

For a given sprinkler geometry and spacing as well as a fixed ceiling height, the water penetration ratio in the gravity regime may be expressed in a power-law relationship [2] as

$$
P=\frac{A D D}{L A D} \sim\left(\frac{\left(\rho_{w} g\right)^{2 / 3}}{\left(\rho_{a} \mu_{r}\right)^{1 / 3}} \frac{d_{c}}{u_{c}}\right)^{C_{2}}
$$

where $C_{2}$ is a positive exponent of order one. Equation (1) was derived based on the assumptions that the likelihood of the water drops reaching the base of a fire plume depends only on the balance of the gravitational force on the individual drop and the upward aerodynamic drag on the drop by the plume gas, and that the plume flow was not affected by the downward water momentum flux. Equation (1) predicts that the water penetration increases with the spray drop size and with decreasing fire intensity. As the fire size is decreased for a fixed water discharge rate (or increasing discharge rate for a fixed fire 
strength), the spray-plume interaction eventually enters into the momentum regime in which equation (1) ceases to be applicable. In this regime, the plume flow is significantly changed by the aggregated droplet momentum flux.

The characteristic diameter of the water drops, $d_{c}$ in equation (1), depends on the water discharge rate and on the fire position relative to the sprinkler axis. For the case when the sprinkler was directly over the fire, $d_{c}$ would be the average size of the water drops in the vicinity of the sprinkler axis. Previous drop size distribution measurement of sprinkler sprays [5] had shown that the average drop size near the sprinkler axis was essentially insensitive to the water discharge rate; a four-fold increase in the water discharge rate caused a decrease in the median drop size of only 10 percent. Furthermore, the present data obtained from the single-sprinkler measurement also tend to indicate that the water penetration ratio is not a function of the water discharge rate. Therefore, in correlating the experimental data for the single-sprinkler condition, $d_{c}$ was assumed to be constant for a given sprinkler and proportional to the sprinkler orifice diameter. With these assumptions, equation (1) then becomes

$$
\frac{A D D}{L A D}=C_{1}\left(\frac{\left(\rho_{w} g\right)^{2 / 3}}{\left(\rho_{a} \mu_{r}\right)^{1 / 3}} \frac{D}{u_{c}}\right)^{C_{2}}
$$

Variation of the factor $\left(\rho_{\mathrm{a}} \mu_{\mathrm{r}}\right)^{1 / 3}$ under the present measurement conditions is less than 10 percent. Thus, the value of $\rho_{\mathrm{a}} \mu_{\mathrm{r}}$ at the maximum plume temperature $(1300 \mathrm{~K})$ is used for all the correlations, and was calculated from [6] to be $7.634 \times 10^{-6} \mathrm{~kg}^{2} / \mathrm{m}^{4} / \mathrm{s}$. The plume centerline velocity at the ceiling elevation is used as the characteristic velocity, $u_{c}$ in equation (2). For rack-storage fire of the FMRC Class II commodity, the plume centerline velocity can be calculated from the following correlations [3]

$$
\begin{aligned}
u_{c}=u_{p} & =4.25\left(\frac{g}{\rho_{a} C_{p} T_{a}}\right)^{\frac{1}{3}}\left(\frac{Q_{c}}{z-z_{o}}\right)^{\frac{1}{3}} \\
z_{o} & =-2.4+0.095 Q_{c}^{\frac{2}{5}}
\end{aligned}
$$

With $z=3.05 \mathrm{~m}$ and $u_{c}$ calculated from equation (3), equation (2) is fitted with the experimental data obtained for the single-sprinkler arrangement, as demonstrated in Figure 4. The values of $C_{1}$ and $C_{2}$ for the best fit of the data are also included in the figure. It is noted that the values of $\mathrm{C}_{1}$ for the three sprinklers are nearly the same and the experimental data are well correlated by equation (2) with the same exponent $C_{2}$ of value 0.75 .

For the cases of two- and four- sprinkler-fire arrangements in which the fire was at a distance from the sprinkler axis, it was found that the mass median diameter of the entire sprinkler 


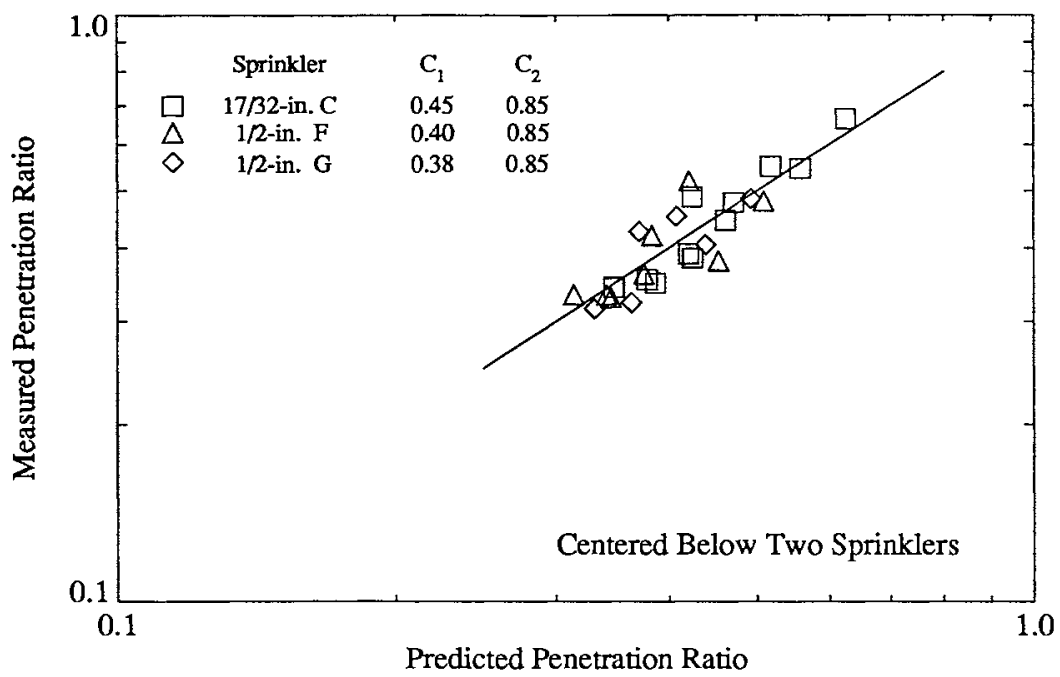

Figure 5. Correlation of the water penetration ratio with equation (5) for the case when the fire was below two sprinklers on the same pipe.

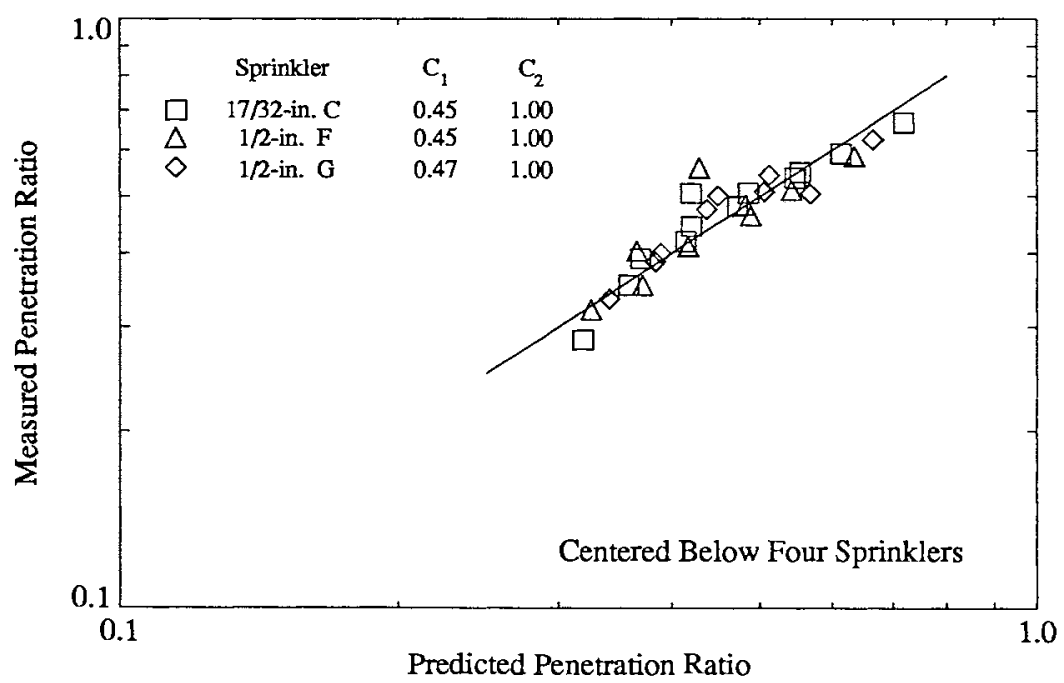

Figure 6. Correlation of the water penetration ratio with equation (5) for the case when the fire was below four sprinklers. 
spray could be used for $d_{c}$ [2]. The mass median diameter is obtained from [5]

$$
d_{c}=d_{m} \sim\left(\frac{\sigma}{\rho_{w}}\right)^{\frac{1}{3}} \frac{D^{2}}{Q_{w}^{2 / 3}}
$$

Substituting (4) into (1), one obtains

$$
\frac{A D D}{L A D}=C_{1}\left(\frac{g^{3 / 2}\left(\rho_{w} \sigma\right)^{1 / 3}}{\left(\rho_{a} \mu_{Y}\right)^{1 / 3}} \frac{D^{2}}{u_{c} Q_{w}^{2 / 3}}\right)^{C_{2}}
$$

Figures 5 and 6 show the correlations of equation (5) with the experimental data obtained for the two- and four- sprinkler arrangements, respectively. The empirical constants $C_{1}$ and $C_{2}$ are also shown in the figures. As in the single-sprinkler case, the experimental data for each arrangement are well correlated with a single value of $\mathrm{C}_{2}$ for the three sprinklers employed in the present investigation.

\section{CONCLUSIONS}

The Actual Delivered Densities (ADD) under rack-storage fires have been studied experimentally for three upright standard sprinklers, using a dedicated ADD apparatus equipped with a fire plume simulator. Power-law correlations for the experimental data have been established for three upright standard sprinklers discharging $3.05 \mathrm{~m}(10 \mathrm{ft})$ above the base of the fire plume simulator. In the case when the fire was centered under a single sprinkler, the water penetration ratio for a given sprinkler and fire size was found independent of the water discharge rate under the present measurement range. The effect, indirectly through $u_{p}$, of the freeburn convective heat release of the fire on the penetration ratio is well correlated by equation (2) with a constant exponent of 0.75 . The water penetration ratio as a function of the water discharge rate and freeburn convective heat release rate correlates well with equation (5) with an exponent of 0.85 for the case when the fire was centered below two sprinklers and a unit exponent when the fire was centered below four sprinklers. Applicability of the present correlations to ceiling clearances other than $3.05 \mathrm{~m}$ is currently under investigation.

\section{NOMENCLATURE}

$\begin{array}{ll}\text { ADD } & \text { Actual Delivered Density } \\ C_{1} & \text { empirical constant } \\ C_{2} & \text { empirical constant } \\ c_{p} & \text { specific heat }(\mathrm{kJ} / \mathrm{kg})\end{array}$


D orifice diameter of sprinkler

$\mathrm{d}_{c} \quad$ characteristic drop size of sprinkler spray

$\mathrm{d}_{m} \quad$ mass median diameter

g acceleration of gravity

LAD water density without fire (Local Applied Density)

$P \quad$ water penetration ratio (ratio of $A D D$ to $L A D$ )

$Q_{c} \quad$ freeburn convective heat release rate $(\mathrm{kW})$

$\mathrm{Q}_{\mathrm{w}} \quad$ water discharge rate

$\mathrm{T}_{\mathrm{a}}$ ambient temperature $(\mathrm{K})$

$\Delta \mathrm{T}_{\mathrm{c}} \quad$ centerline excess temperature (above ambient) of the plume

$\Delta \mathrm{T}_{\mathrm{o}}$ off-center excess temperature (above ambient) of the plume

$u_{c} \quad$ characteristic velocity $(\mathrm{m} / \mathrm{s})$

$u_{\mathrm{p}}$ plume centerline velocity $(\mathrm{m} / \mathrm{s})$

$\mathrm{z}$ vertical distance from the water collection pans (m)

$\mathbf{z}_{\mathbf{o}} \quad$ virtual origin

$\mu_{s} \quad$ mixture (water/air) viscosity according to the $1 / 3$ rule

$P_{8} \quad$ air density

$\rho_{w} \quad$ water density

$\sigma \quad$ surface tension (water/air)

\section{REFERENCES}

1. Yao, C., "The Development of the ESFR Sprinkler System," Fire Safety Journal, 14, 65-73, 1988.

2. Heskestad, G., "Sprinkler Performance as Related to Size and Design, Vol. I Laboratory Investigation," FMRC Technical Report, No. 22437, 1979.

3. You, H-Z and Kung, H-C, "Strong Buoyant Plumes of Growing Rack Storage Fires," Twentieth Symposium (International) on Combustion, The Combustion Institute, pp. 1547-1554, 1984.

4. Chan, T-S, Kung, H-C, Yu, H-Z and Brown, W. R., "Sprinkler Performance Evaluation of Selected U.S. Spray and European Conventional Sprinklers, Vol. I Measurements of Sprinkler Performance Parameters," FMRC Technical Report, J. I. OVOJ2.RA, 1993.

5. You, H-Z., "Investigation of Spray Patterns of Selected Sprinklers with the FMRC Drop Size Measuring System," Proceedings of the First International Symposium on Fire Safety Science, pp. 1165-1176, Hemisphere, 1986.

6. Yuen, M. C. and Chen, L. W., "On Drag of Evaporating Liquid Droplets," Combustion Science and Technology, 14, 147-154, 1976. 